\title{
A precise past
}

In its day it served both as a thing of beauty and as a precise, portable calculator and observational tool. The astrolabe was used in astronomy, navigation and surveying, and by Muslims to determine the direction of Mecca and the times of prayer. An important scientific instrument from antiquity to the Renaissance, it was so perfectly designed that it remained in its essentials unchanged for 1,500 years.

Astrolabes at Greenwich, edited by Koenraad van Cleempoel (Oxford University Press, £99.50, \$179.50), explores the collection of more than 50 astrolabes at the National Maritime Museum at Greenwich, London. The engraved Safavid example shown here, from around 1660, exquisitely fuses art and science

B.K.

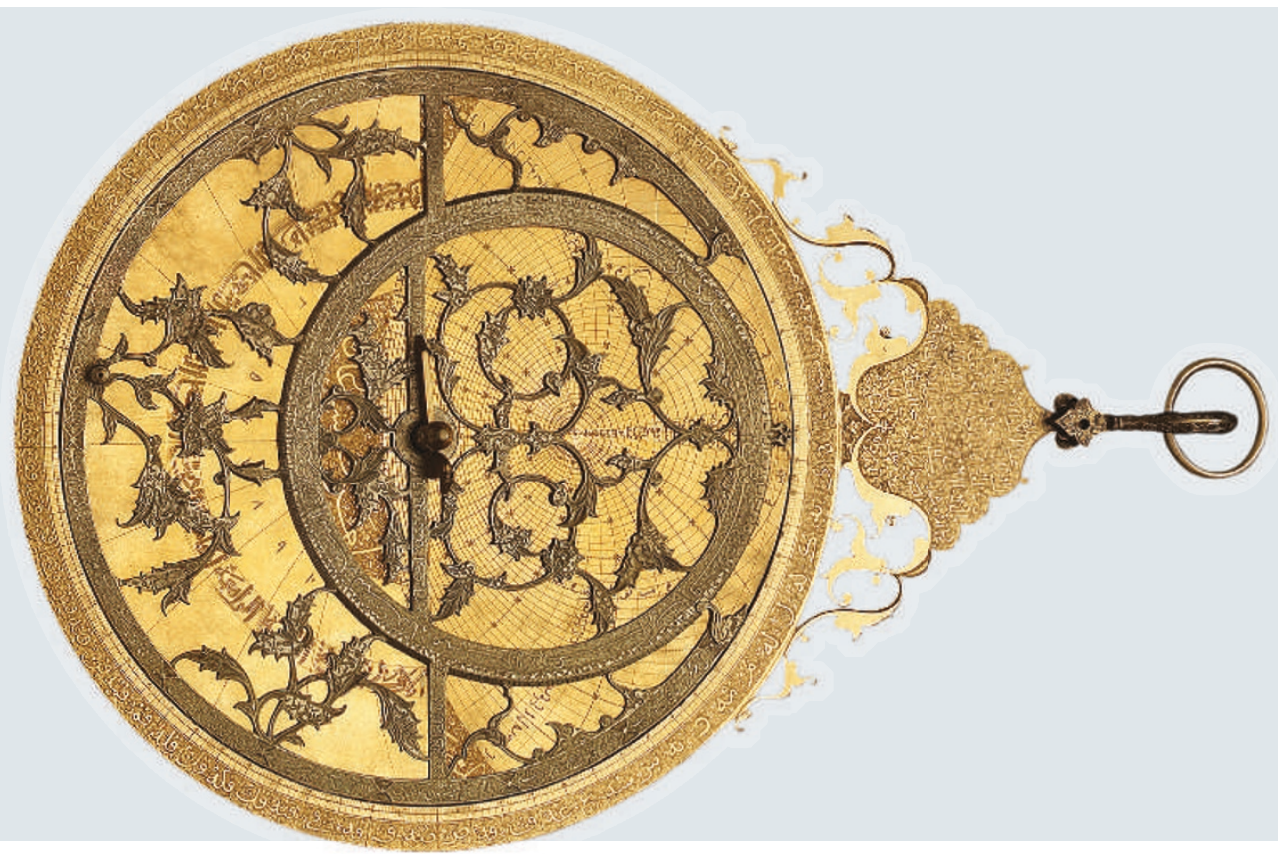

\section{Having faith}

\section{Minds and Gods: The Cognitive \\ Foundations of Religion \\ by Todd Tremlin \\ Oxford University Press: 2006.256 pp. $\$ 30, £ 17.99$}

\section{Ann Cale Kruger and Melvin Konner}

For millennia, religious faith has driven human history, for good or ill. Faith has inspired architectural feats and horrific destruction, soaring music and hateful speech, personal sacrifice and cold-blooded murder. For centuries, historians, philosophers, anthropologists and theologians have wrestled with understanding the mystery and power of religion. Most psychologists have not. But now a small group of thinkers is turning to them for no less than a full scientific explanation of religious beliefs. In Minds and Gods, Todd Tremlin bravely attempts to discover the "natural cognitive foundations" of religious thought and, more specifically, seeks a "complete, detailed explanation of the relation of heavenly gods and earthly minds".

The book is a partial success. More than a third of it explains in detail that human evolution happened, that science has discovered many interesting things about the brain, and that the mind is fundamentally modular. The first two of these conclusions are banal, and the third is more controversial than it seems here. But none of them was needed in such detail to prepare for the book's central thesis.

Tremlin argues that universal human cognitive processes naturally produce gods. In particular, an agency detection device (ADD) and a theory-of-mind module (ToMM) lead us to expect an agent behind every event, and to expect that agent to have a mind. We err on the side of attributing agency where there isn't any - a trait that no doubt served our ancestors well. And we endow the presumed agent with mental properties that, super-powers notwithstanding, are similar to our own.

The problem is that in reducing complex functions to elemental components, something gets left behind. Tremlin concedes that "ADD and ToMM are not the only mental mechanisms that underpin religious thought...gods evoke intense feelings and emotional experiences", and argues that "belief in gods indeed is largely an activity of the heart". Yet he devotes only a few pages to emotion.

The twin human needs for attachment and meaning form the foundation of faith. Unlike other animals, we foresee the distant future, and the vision is unsettling. We ask why we are here and whether life has a purpose; we are anxious about being alone. Religious beliefs may recruit the cognitive mechanisms outlined here, but they are largely fuelled by fear, loneliness and longing. Parents, friends and leaders may abandon or disappoint us, but gods do not. They care about our behaviour and destiny, and know what we do for good and ill, infusing every moment with meaning. Any claim to understand belief must seriously address not just human cognition, but the rich and complex human needs that pervade and energize thinking.

Religion is scarcely uncharted scientific territory. Darwin, in The Descent of Man, wrote that religious devotion is highly complex, "consisting of love, complete submission to an exalted and mysterious superior, a strong sense of dependence, fear, reverence, gratitude, hope for the future, and perhaps other elements". William James (not cited by Tremlin) and
Sigmund Freud (mentioned in passing), the founders of different psychological traditions, both wrote books about the mental processes in religious ideas and practices. James emphasized the inner religious struggle between melancholy and happiness, and pointed to trance as a cognitive mechanism. Freud stressed fear and pain, the need for a powerful parent to care for us, the obsessional nature of ritual, and the hypnotic state a community can induce.

One of us has some religious faith, the other once did. Like most thoughtful people, we wonder where and how faith might be instantiated in mind and brain. There must be a cognitive mechanism that allows a belief in gods, but there must also be more than just conceptual tools to explain the range of behaviours inspired by belief. People routinely believe many things for which there is no evidence, so perhaps it is really science and scepticism that are unnatural and need explaining.

This book represents the emerging field of the cognitive science of religion, and it adds something to our understanding: the natural human penchant for detecting agency and for imagining other minds allow us to conceptualize gods, and thus serve the emotions that motivate religious faith. Perhaps in the future, Tremlin and others working in this new field will attempt to integrate it with older ideas to develop a more comprehensive psychology of religion. Meanwhile, it is good, especially in a world endlessly troubled by religious differences, to have a new theoretical analysis suggesting that there are core religious beliefs that transcend our differences and that stem from universal features of the human mind. Ann Cale Kruger teaches developmental psychology at Georgia State University. Melvin Konner, author of The Tangled Wing, teaches anthropology and behavioural biology at Emory University, Atlanta, Georgia 30322, USA. 